\title{
Moment-by-moment interpersonal behaviors in poor vs. good psychodynamic psychotherapy outcomes: Does complementarity say it all?
}

\author{
Davide Margola, Monica Accordini, Emilio Fava \\ Catholic University of Milan, Italy
}

\begin{abstract}
Can patient-therapist moment-by-moment transactions uncover contrary treatment outcomes? The current study answers this question by analyzing the transcripts from eight therapy sessions of 20 patients each, for a total of 160 sessions and nearly 30,000 units of analysis. Patients were matched into ten pairs, each having the same diagnosis and the same clinician but with opposite treatment re sults: Ten patients were classified as responders (i.e., good-outcome patients) and as many as nonresponders (i.e., poor-outcome patients). Patient and therapist behaviors were coded using the Structural Analysis of Social Behavior (SASB) model. Overall, patients and therapists engaged in complementary relational patterns: Good-outcome patients tended to adopt loving and protecting interaction styles, similarly, therapists treating good-outcome cases employed protection and self-disclosure behaviors. In contrast, poor-outcome patients tried to interpersonally separate from the therapist, and both - patients and therapists alike - exhibited attacking and recoiling behaviors. However, when taking a closer look, i) separation appeared to be disruptive per se, that is, beyond any evidenced interpersonal asymmetry; ii) self-disclosure on the therapist side turned out to be supportive of therapeutic complementarity; iii) when facing failure, highly experienced therapists seemed to indulge into noncomplementary or even hostile behaviors. Findings confirm that the target of the patient-therapist transferential transactions should be distinguished from transactions regarding other people or other life circumstances in order to avoid misleading interpretation of data and, consequently, conducting therapy based on misleading grounds.
\end{abstract}

Key words: Process-outcome research; Structural Analysis of Social Behavior (SASB); Interpersonal behavior transactions; Complementarity; Self-disclosure.

\section{Introduction}

The patient-therapist relationship is widely recognized as the most significant contributing factor to psychotherapy

Correspondence: Davide Margola, Faculty of Psychology, Catholic University of Milan, Via Nirone 15, Milan, MI 20123, Italy. Tel.: +39.02.7234.5943

E-mail: davide.margola@unicatt.it

Citation: Margola, D., Accordini, M., Fava, E. (2020). Momentby-moment interpersonal behaviors in poor vs. good psychodynamic psychotherapy outcomes: Does complementarity say it all? Research in Psychotherapy: Psychopathology, Process and Outcome, 23(2), 167-179. doi: 10.4081/ripppo.2020.454

Conflict of interest: the authors declare no potential conflict of interests.

Received for publication: 12 February 2020.

Accepted for publication: 29 June 2020.

This work is licensed under a Creative Commons Attribution NonCommercial 4.0 License (CC BY-NC 4.0).

${ }^{\circ}$ Copyright: the Author(s), 2020

Licensee PAGEPress, Italy

Research in Psychotherapy:

Psychopathology, Process and Outcome 2020; 23:167-179

doi:10.4081/ripppo.2020.454 outcome (e.g., Hill \& Knox, 2009; Lambert \& Barley, 2001), not only in psychodynamic-interpersonal therapies (e.g., Keijsers, Schaap, \& Hoogduin, 2000; Waddington, 2002). Such evidence credits the therapeutic relationship with the role of a powerful predictor of treatment response, for better or for worse, rather than ad hoc therapeutic techniques (Lingiardi \& Muzi, 2018; Norcross \& Wampold, 2011; Wong \& Pos, 2012; see also, Lingiardi, Muzi, Tanzilli, \& Carone, 2018). Moreover, such findings are fully confirmed irrespective of whether the therapeutic relationship is conceived as the real relationship (Gelso, 2009), the patient-therapist alliance (Horvath, Del Re, Flückiger, \& Symonds, 2011), or the so-called internalized transference (Høglend \& Gabbard, 2012). These three constructs are strictly interrelated and simultaneously operate within the clinical setting (Fava \& Vigorelli, 2006). The underlying relational process can be viewed as an index of the nature and extent of therapeutic change (Anchin \& Kiesler, 1982; Henry, Schacht, \& Strupp, 1990; Orlinsky, Rønnestad, \& Willutzki, 2004), of the way patients learn to treat themselves (Aliprandi, Capelli, \& Marchesi, 2009; Capelli et al., 2005), and — on an opposite note — of the tendency to maintain maladaptive relationships in a number of patients not benefiting from professional clinical care (Beutler, Rocco, Moleiro, \& Talebi, 2001; Lutz et al., 2006; von der Lippe, Monsen, Rønnestad, \& Eilertsen, 2008).

Within such a scenario, virtually all schools of therapy 
agree there are a few necessary (for some, sufficient) conditions that are critical to the final outcome. Such conditions may go under different names (e.g., from collaborative reciprocity to interactive coordination, from patient-therapist cooperation to some sort of congruence between the patient's symptoms and the techniques used), but they all seem to underlie the same basic concept: That of complementarity (Caspar, Grossmann, Unmüssig, \& Schramm, 2005; Thompson, Schwartzman, D'Iuso, Dobson, \& Drapeau, 2018), here conceived in its relational meaning (Ahmed, Westra, \& Constantino, 2012; Coady, 1991; Critchfield, Henry, Castonguay, \& Borkovec, 2007; Tasca et al., 2011). In interpersonal complementarity, "a given behavior is thought to pull for its complementary response" (Critchfield et al., 2007, p. 39), but this does not necessarily imply that therapists are to indistinctly support patients' stances or claims (e.g., patients' whining shouldn't pull for pity and indulgence on the therapist's side; Caspar et al., 2005). However, the opposite behavioral pattern, i.e., asymmetry or "unproductive noncomplementarity" (Caspar et al., 2005, p. 99), which occurs when a specific behavior elicits an opposite as well as incongruent response, has been proven to be disruptive and maladaptive. The research question underlying the present study is whether complementarity is a one-size-fits-all solution or whether asymmetry, under certain circumstances, may be more clinically useful (Anderson, Knobloch-Fedders, Stiles, Ordoñez, \& Heckman, 2012; McWilliams, 2011; Samstag et al., 2008).

\section{A three-foci perspective of investigation: Previous research results}

While concepts like real relationship and therapeutic alliance have now gained general consensus, both in terms of their conceptual (McWilliams, 2011) as well as operational (Critchfield et al., 2007) definition, transference is much more debated, despite the historic attempt at its operationalization through the Core Conflictual Relationship Theme (CCRT; Luborsky \& Crits-Christoph, 1990). From false link to the actualization of the there-and-then into the here-and-now (Freud, 1920; see also, McWilliams, 2011), in a sort of relational stereotype based on repetition compulsion, in this paper we adopt a definition according to which transference occurs each time our behaviors reveal that we are in the presence of an object that is not egocentrically the self (Bion, 1963). Using an observerbased, well-known, and validated coding system, we will examine patient and therapist proximal behaviors, particularly focusing on the statements patients and therapists make when the object is not an unspecified other but rather the therapist in the case of the patient (and the patient in the case of the therapist). In other words, we will focus on the statements patients and therapists make when addressing each other directly, that is, on the patient-therapist dyad as the specific target of the ongoing psychotherapy process (Wong \& Pos, 2012).
Moreover, there is a general consensus about the conditions that help or hinder treatment outcome (e.g., Caspar et al., 2005). However, research results are rarely devoid of ambiguity, especially in the case of poor treatment responses (Anderson et al., 2012). On this note, following Allport (1937), a lack of response to psychotherapy might be connected to the fact that patients tend to develop a dysfunctional autonomy, which-once set in motion-becomes habitual as well as damaging. On their end, Karen Horney (1936), then Joan Riviere (1936), and, more comprehensively, Lorna Benjamin $(2002 ; 2003)$ demonstrated how treatment failure is strictly associated with those figures identified as "important people and their internalized representations" (i.e., IPIRs; Benjamin, 2002, p. 25). In particular, the need to maintain psychic proximity with and receive love and encouragement from dysfunctional IPIRs can lead to a particular form of resistance to change (Beutler et al., 2001), occurring when the conditions are such that change may be impossible or even paradoxical. If this is true in the case of significant others, it might as well be true in the case of the patient-therapist relationship (Henry et al., 1990). Following Amadei, "[...] feelings of rejected love $[\ldots]$ cause the patient to obstinately repeat a traumatic behavior pattern in a desperate attempt to maintain psychic proximity with an object that they feel unreachable or too demanding." (Amadei, 2001, p. 65; the translation and Italics are our own). Once again, the current study specifically focuses on the other within the therapeutic dyad, rather than on a generic other (Wong \& Pos, 2012).

Lastly, when focusing on the therapist's role, studies on the effects of their training on treatment responses are still lacking systematization (Beutler et al., 2004), with the result of jeopardizing the quality of research findings and concluding that this variable does not make a difference (Mahrer, 1999) or, when it does, such difference is mediated by other variables (e.g., interpersonal skills irrespective of years of experience in clinical practice; Lingiardi et al., 2018; Stein \& Lambert, 1984). On the contrary, it is quite indubitable that even experienced clinicians might engage in destructive and dysfunctional dynamics (e.g., Accordini, Browning, Gennari, McCarthy, \& Margola, 2017; Ackerman \& Hilsenroth, 2001), especially when patients are characterized by negative or ambivalent IPIRs, overall hostility, early negative responses to treatment, and, more in general, low levels of interpersonal complementarity (e.g., Henry, Schacht, \& Strupp, 1986; Henry et al., 1990; Lambert \& Ogles, 2004; Lingiardi \& Muzi, 2018; Orlinsky et al., 2004; Tanzilli, Muzi, Ronningstam, \& Lingiardi, 2017; von der Lippe et al., 2008).

Based on these findings - before illustrating and discussing the results of the current study - we will review the Structural Analysis of Social Behavior (i.e., SASB; Benjamin, 1974; 1979; 1984; 1994) approach as our preferred method for analyzing treatment process and the underlying interpersonal dynamics between patients and therapists. Along the way we will clarify our operational 
definition of responders/nonresponders and describe our research coding procedure and design.

\section{The Structural Analysis of Social Behavior model}

Structural Analysis of Social Behavior (SASB) (see Fava \& Vigorelli, 2006, for a comprehensive review) is a sophisticated circumplex model in which complementarity as well as transference are key predictive components. It assumes that there are three basic dimensions underlying all human interactions: i) focus of transaction (i.e., focus on the Other $v s$. the Self $v s$. the Introject), ii) affiliation (i.e., love $v s$. attack), and iii) interdependence (i.e., emancipation $v s$. control). These latter dimensions can be represented in a Cartesian space, where two independent axes of equal length, one horizontal (i.e., affiliation) and one vertical (i.e., interdependence), result in four quadrants. The first dimension (i.e., focus of transaction) outlining the person or internalized object to whom the attention or transaction is being directed, is marked in Figure 1 by variations in font. Specifically, clusters in bold type refer to the transitive Other focus (e.g., "You seem not to understand my goals in this therapy"). Underlined clusters refer to the intransitive Self focus as a reaction to others (e.g., "Now I want to tell you what my goals are in this therapy"). Finally, clusters in Italics refer to the Introject focus (as self-concept or introjected action, here conceived as the tendency to treat oneself as one has been habitually treated by others) (e.g., "I am not willing to take this risk in this therapy").

Figure 1 shows a cluster model encompassing 24 psychometrically validated codes (Benjamin, 2002; see also, Benjamin, Rothweiler, \& Critchfield, 2006; Constantino, 2000), which result in an octant model, less complex than the original one (Fava \& Vigorelli, 2006). Each of the 24 cluster codes receive a double numeric coding: The first number, ranging from 1 to 3 , indicates the surface or focus of transaction (i.e., Other, Self, and Introject), here superimposed on one another. The second number, ranging from 1 to 8 , indicates the cluster code. Such codes are the result of the combination between the affiliation and interdependence axes: Those in the first right-sided half of the octant model (particularly, clusters 2-4) typically refer to adaptive interpersonal transactions; those in the second left-sided half (particularly, cluster 6-8) typically refer to maladaptive interpersonal transactions (see for example, Pincus, Dickinson, Schut, Castonguay, \& Bedics, 1999). Likewise, a cluster code on an extreme of the two axes such as separate (2.1) is neutral in terms of affiliation but simultaneously implies the maximum degree of differentiation (in this specific case from the point of view of the intransitive Self). Again, cluster codes such as protect (1.4) or disclose (2.2) imply a moderate degree of (adaptive) affiliation as well as a moderate degree of (adaptive) interdependence (from the point of view of the transitive Other [cluster 1.4, protect] and intransitive Self [cluster 2.2 , disclose], respectively).

\section{The current study}

This study examines patient-therapist microanalytic (proximal) transactions and therapy outcomes. Specifically, during the first year of therapy, moment-by-moment transactions were measured by means of the Structural Analysis of Social Behavior (i.e., SASB; Benjamin, 2002; Benjamin et al., 2006) clusters, and these were used to compare poor vs. good treatment outcomes (for another example of moment-by-moment observational data to distinguish contrary treatment responses, see Margola, Donato, Accordini, Emery, \& Snyder, 2018; see also, Frommer \& Rennie, 2001; Lepper \& Riding, 2006).

In so doing, our main goal was to investigate whether observational measures, such as those at the basis of the SASB model, shed light onto the patient-therapist interactions (Wong \& Pos, 2012). According to the theoretical three-foci perspective highlighted above, we intended to investigate: i) whether there is a complementarity between patient-therapist mutual (transference) behaviors; ii)

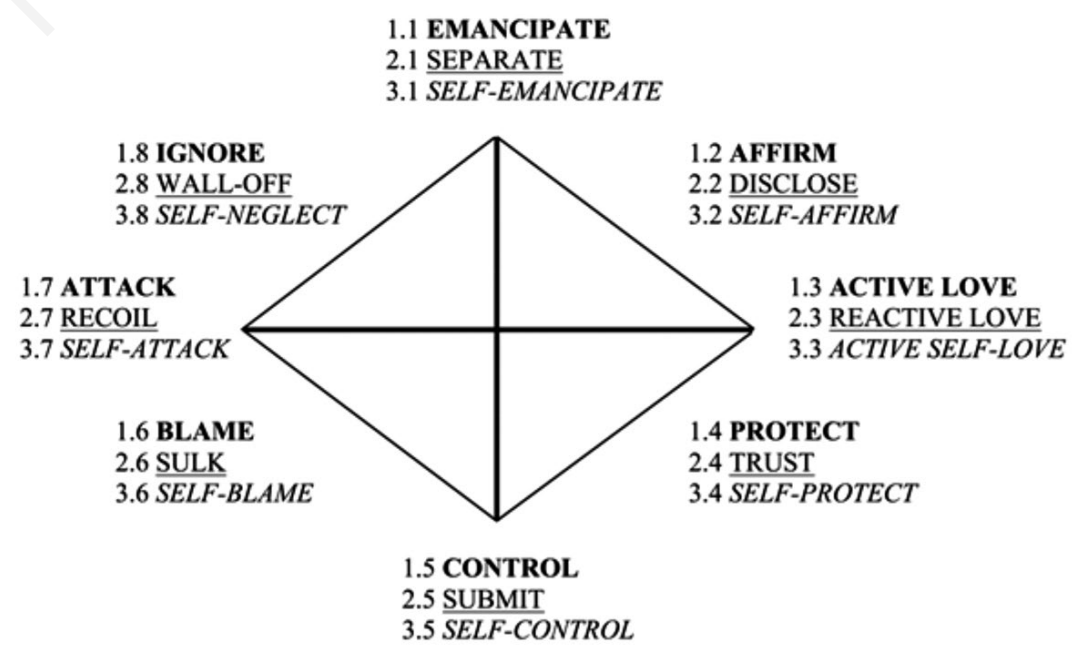

Figure 1. The simplified SASB cluster model (adapted from Benjamin, 2002). 
whether interpersonal processes, including self-disclosure on therapists' side, have some bearing on patients not responding to psychotherapy; iii) under what circumstances well-trained therapists experience failure (Caspar et al., 2005; Norcross \& Wampold, 2011; von der Lippe et al., 2008).

The overall point is this: If patients are highly receptive to the therapist's behavior (Horvath et al., 2011; Orlinsky et al., 2004), the latter should drive the context, without counteracting (Margola et al., 2018) or discouraging and weakening oneself (von der Lippe et al., 2008) even in the face of asymmetry and hostility.

\section{Methods}

\section{Participants}

Twenty patient-therapist dyads participated in this research. These dyads were divided in two equal groups of poor- and good-outcome cases. Patients in the two matched groups were treated by the same group of therapists and were given a diagnosis in the same pathological (neurotic) spectrum. All 20 patients attended weekly psychotherapy sessions for a minimum of one year and a half (and a maximum of two years and a half; $M$ months=23.80, $S D=4.26$ ). All but three (who had previously initiated a therapy but had unilaterally chosen to terminate it after a few [2-5] sessions) of the participants had never undergone long-term psychotherapy. Therapy consisted of 50-minute individual sessions and was conducted with no intrusion by the research staff. Additionally, therapists were blind to the research goals. Participants were mixed outpatients at a large University Hospital in northern Italy and were diagnosed - according to the DSM-IV-TR (American Psychiatric Association, 2000) via SCID-I and -II (i.e., Structured Clinical Interview for DSM-IV, Axis I and II Disorders; Hilsenroth \& Segal, 2004) —with mood and anxiety problems. Overall, $64 \%$ of patients being diagnosed with this type of disorders had at least one additional concurrent anxiety or mood disorder, and $79 \%$ of them had experienced one Axis I disorder previously in their life, in the same pathological spectrum. With regards to comorbidity between Axis I and Axis II disorders, only patients showing no evidence of comorbidity between clinical and personality disorders were included in the study. Moreover, patients younger than 18 years, having psychotic symptoms, abusing drugs or alcohol, and/or needing emergency treatment and subsequent hospitalization, were excluded from the research. Ten male patients (six were part of the poor-outcome group and four were part of the good-outcome group) and ten female patients (four were part of the pooroutcome group and six were part of the good-outcome group) participated in the research. Average patient age was 36 years $(S D=10.82$, range $=24-69)$ and average years of education was $13(S D=3.64$, range $=8-18)$. Nine pa- tients were either married or cohabiting, whereas the remaining 11 were divorced or single. Six patients had children and 14 were childless. These 20 patients were treated by nine licensed clinicians who described themselves as having a shared Freudian psychodynamic clinical approach. Eight clinicians treated one poor-outcome and one good-outcome patient; one clinician treated two of each (for a total of four patients). Therapists were four females and five males, averaging 47.8 years of age $(S D=7.1)$ and 16.8 years of clinical experience $(S D=3.5)$.

\section{Procedures}

The research was approved by the University Hospital Institutional Review Board and Ethical Committee, and all participants completed a consent form. Prior to the beginning of therapy, patients completed the Symptom Checklist-90-R (SCL-90-R; Derogatis, 1994), and the same scale was also used both at six and 12 months after therapy commencement. Ordinary statistical tests performed on patients' scores before the beginning of therapy did not reveal any significant differences between the poor- and good-outcome groups on both the self-reported GSI scores globally and the nine SCL-90-R symptom dimensions separately (all $p \mathrm{~s}$ via $t$-test $>0.10$ ). Moreover, no significant differences were found for age, education level, and socio-economic status (all $p$ s via $t$-test $>0.10$ ). On the contrary, GSI scores calculated at 12 months after therapy commencement showed a significant difference between the $\operatorname{good}(M=0.40, S D=0.19)$ and poor $(M=0.94$, $S D=0.26)$ outcome patient group $[t(31.65)=-2.39, p<0.01$, $g=2.37$.

The Reliable Change Index (RCI; Jacobson, 1988; Jacobson, Follette, \& Revenstorf, 1984) was applied to the SCL-90-R Global Severity Index (GSI) scores, which represent the average of all 90 responses. The RCI is defined as the minimum statistically significant individual change between pre- and post-treatment scores. The RCI score is calculated by dividing the difference between pre- and post-treatment scores by their standard error difference. A change can be considered statistically significant if the patient's post-test score exceeds the cut-off based on the nonclinical population scores and, at the same time, is greater than the RCI value. Based on previous studies (Luca, Ruta, Signorelli, Petralia, \& Aguglia, 2015; Schurle Bruce \& Arnett, 2008), we used a cut-off score of 0.70 for GSI scores. Both SCL-90-R symptom index values as well as GSI values at Time 1 were correlated with the same indexes at Time 2 . With the only exception of paranoid ideation and hostility, all the correlations were statistically significant at the 0.01 level. In particular, Cronbach's alpha for the GSI scores was 0.76 . These values were then compared with score intervals from Schmitz et al.'s (Schmitz, Hartkamp, Brinschwitz, Michalek, \& Tress, 2000) grid to compute the RCI and determine the composition of the two (good- and poor-) outcome groups. Ex post scrutiny of patient clinical re- 
ports confirmed appropriateness of the composition of the two opposite outcome groups.

All psychotherapy sessions were audio-recorded and then transcribed verbatim. Eight 25-minute (i.e., half session) transcripts were coded for each patient. To rule out potential differences in the patient-therapist transactions due to session timing, the first and second halves of each session were coded in a counterbalance manner. Since several authors (Blomberg, Lazar, \& Sandell, 2001; Ferrari, Pinzi, Camarda, \& Roustayan, 2005; Howard, Kopta, Krause, \& Orlinsky, 1986) reported the first year of treatment as being the most predictive of therapy outcome, eight sessions were chosen within this timeframe. To avoid the over-representation of specific time periods, the year was divided into four quarters $(\mathrm{T} 0=$ zero months, $\mathrm{T} 1=$ four months, T2=eight months, T3=12 months) and two sessions for each quarter were considered. Sessions transcripts were initially broken down into thought units, similarly to previously aligned research (e.g., Henry et al., 1986, 1990; Henry, Schacht, Strupp, Butler, \& Binder, 1993). Thought units refer to speech portions expressing a complete thought. Three independent judges coded each of the identified thought units using the SASB model. The coding procedure required four steps for each thought unit: i) establishing the focus (i.e., deciding whether the speaker was focusing on the Other, the Self, or the Introject); ii) rating the degree of affiliation (i.e., love vs. attack; horizontal axis) on a 5-point Likert scale; iii) rating the degree of interdependence (i.e., emancipation vs. control; vertical axis) on a 5-point Likert scale; iv) placing the thought unit in the appropriate place on the octant SASB cluster model (see Figure 1). Those cases where more than one cluster was deemed appropriate, were classified as complex communications (Constantino, 2000; Samstag, 1998) and were assigned to more than one cluster. Given the paucity of most of these complex codes, only the two most frequent ones were retained for further analyses: i) mixed interdependence (clusters 1.2, affirm, and 1.5, control; 895 occurrences), e.g., when the therapist controls yet supportively encourages the patient's openness ("You are heard. Tell me more about this issue. In a way, it also concerns the two of us"); ii) mixed focus (clusters 1.4, protect, and 2.2, disclose; 363 occurrences), e.g., when the patient positively comments on the therapist's action and, at the same time, discloses his/her own positive feelings towards the therapist ("On that occasion I felt understood and heard when you acknowledged my struggles with my family"). This mixed code applies when the focus of transaction is simultaneously directed towards the Other and the Self.

The cases in which the judges were unable to assign the thought unit to any of the eight (basic) clusters or the two complex (mixed) clusters, were classified as incomprehensible, and were not retained for further analyses. The present research, therefore, used a total of ten cluster codes. The three judges, all trained psychotherapists, were blind to patients' identity as well as of treatment outcome, and-before the research started-had received a sixmonth theoretical and practical training on the SASB coding procedure.

\section{Data analytic strategies}

\section{Inter- and intra-rater reliability}

Fleiss's Kappa (Fleiss \& Cohen, 1973) was used to assess inter-rater reliability. After the three judges received an intensive theoretical and practical training, the scoring procedure was piloted on a therapy transcript sample (202 thought units) that was not included in this study. As expected, the highest $k$ values were found for the clusters regarding the two relational foci surfaces, whether transitively or intransitively (i.e., Other and Self) (mean $k=0.92$, range $=0.89-0.95$ ) (Henry et al., 1990). Generally, regarding the $8 \times 3$ cluster codes, $k$ values remained above the acceptability threshold (mean $k=0.76$, range $=0.73$ $0.80)$. The lowest values were observed for the reliability of Introject focus (mean $k=0.60$, range $=0.54-0.65$ ). Given this lower reliability and, particularly, the fact that in interpersonal process-outcome research-as the one implemented in this study - the Introject focus is not commonly used (Constantino, 2000), these surface scores were not retained for further analyses. Cohen's Kappa (Cohen, 1968) was used to test intra-rater reliability (Lord \& Novick, 1968). To assess stability within raters across time, each judge coded all transcripts twice: At the beginning of the research (i.e., after data collection) and six months later. All three judges showed an excellent level of reliability across time on all surfaces (Other focus $k$ values $=1$; Self focus $k$ values range $=0.81-0.89$; Introject focus $k$ values range $=0.71-0.86)$. These results are not surprising as the Other focus (e.g., "You seem not to understand me") is almost always clear, whereas the Introject focus (e.g., "I don't quite understand it") is not as clear because it often has an implicit presumed other (i.e., "I don't quite understand what you've just told me").

\section{Statistical analyses}

First, a set of chi-square tests were used to assess whether therapy outcome was associated with the overall number of thought units for each of the two foci surfaces considered in both the patient and therapist groups. Next, consistent with prior consolidated research (Constantino, 2000; Henry, 1996; Henry et al., 1986, 1993; Samstag, 1998), two $2 \times 2 \times 10$ (i.e., focus $\times$ outcome $\times$ cluster) MANOVAs were conducted on the patient and therapist transactions, separately. Before running the analyses, the observed frequencies were weighted by the grand mean of thought units of patients and therapists respectively. Such a weighting procedure allows one to reduce artifacts due to differences in the amount of talk turns across dyads, as well as to minimize the main effect of poor $v s$. good therapy outcomes. Given the positively skewed nature of the data and the unequal variance distribution 
across groups, square root transformations of the weighted scores were then used. Finally, $p$ values were corrected for multiple testing using the Holm-Bonferroni method.

\section{Results}

When therapists' and patients' behaviors were compared, differences with reference to the focus of transaction were noticed. As one might expect in routine therapy, therapists tended to focus on the Other $(77.04 \%$ of cases) and patients tended to focus on the Self ( $83.25 \%$ of cases). However, therapists treating poor-outcome patients showed intransitive personal behaviors focused on the Self to a greater extend if compared to those therapists treating good-outcome patients $\left[\chi^{2}(1,13,216)=79.25, p<0.001\right]$. Similarly, patients in the poor-outcome group directed their behaviors towards the Other more than those patients in the good-outcome group $\left[\chi^{2}(1,16,481)=171.77, p<0.001\right]$.

In this direction, two MANOVAs on therapists' and patients' transactions were conducted with weighted cluster frequencies as dependent variables and focus and outcome as independent variables. Data were tested for both main effects of focus and outcome, as well as for their interaction (nested) effects (i.e., focus * outcome). Results and corresponding effects for focus, outcome, and focus * outcome are presented in Tables 1, 2, and 3, where $p$ values have been corrected for multiple testing. When

Table 1. Tests of Between-Subject Effects for Focus.

\begin{tabular}{lcccccccccccccc}
\hline & \multicolumn{1}{c}{ Therapist } & \multicolumn{1}{c}{ Patient } \\
\hline Cluster (Code) & df & $\begin{array}{c}\text { Other } \\
\text { focus } \\
\text { mean }\end{array}$ & $\begin{array}{c}\text { Self } \\
\text { focus } \\
\text { mean }\end{array}$ & $\begin{array}{c}\text { Mean } \\
\text { square }\end{array}$ & F & Sig. & $\begin{array}{c}\text { Part. } \\
\boldsymbol{\eta}^{2}\end{array}$ & df & $\begin{array}{c}\text { Other } \\
\text { focus } \\
\text { mean }\end{array}$ & $\begin{array}{c}\text { Self } \\
\text { focus } \\
\text { mean }\end{array}$ & $\begin{array}{c}\text { Mean } \\
\text { square }\end{array}$ & $\begin{array}{c}\text { F } \\
\text { Sig. }\end{array}$ & $\begin{array}{c}\text { Part. } \\
\boldsymbol{\eta}^{2}\end{array}$ \\
\hline 1. Emancipate-Separate & 1 & 0.00 & 0.23 & 6.97 & 30.45 & $0.00^{*}$ & 0.00 & 1 & 0.01 & 0.08 & 3.60 & 16.29 & $0.00^{*}$ & 0.00 \\
\hline 2. Affirm-Disclose & 1 & 0.27 & 2.12 & 244.95 & 137.90 & $0.00^{*}$ & 0.01 & 1 & 1.27 & 0.62 & 3.39 & 1.59 & 0.40 & 0.00 \\
\hline 3. Active love-Reactive love & 1 & 0.02 & 0.02 & 0.38 & 2.35 & 0.33 & 0.00 & 1 & 0.10 & 0.01 & 1.20 & 11.34 & $0.00^{*}$ & 0.03 \\
\hline 4. Protect-Trust & 1 & 0.38 & 0.06 & 87.97 & 45.17 & $0.01 *$ & 0.00 & 1 & 0.02 & 0.10 & 607.10 & 470.13 & $0.00^{*}$ & 0.03 \\
\hline 5. Control-Submit & 1 & 0.13 & 0.87 & 115.26 & 113.07 & $0.00^{*}$ & 0.01 & 1 & 0.53 & 0.13 & 126.11 & 171.27 & $0.00^{*}$ & 0.01 \\
\hline 6. Blame-Sulk & 1 & 0.01 & 0.01 & 0.00 & 0.11 & 0.74 & 0.00 & 1 & 0.06 & 0.02 & 4.51 & 88.55 & $0.00^{*}$ & 0.04 \\
\hline 7. Attack-Recoil & 1 & 0.00 & 0.00 & 0.00 & - & - & - & 1 & 0.00 & 0.01 & 4.51 & 88.55 & $0.00^{*}$ & 0.04 \\
\hline 8. Ignore-Wall-off & 1 & 0.00 & 0.03 & 0.11 & 2.56 & 0.33 & 0.00 & 1 & 0.00 & 0.01 & 0.04 & 1.60 & 0.40 & 0.00 \\
\hline 9. Mixed interdependence & 1 & 0.06 & 0.00 & 1.06 & 6.83 & $0.04^{* *}$ & 0.00 & 1 & 0.11 & 0.00 & 29.04 & 91.93 & $0.00^{*}$ & 0.01 \\
\hline 10. Mixed focus & 1 & 0.00 & 0.00 & 0.02 & 5.37 & 0.89 & 0.00 & 1 & - & - & - & - & - & - \\
\hline
\end{tabular}

*, significant at $\mathrm{p}<0.01 ; * *$, significant at $\mathrm{p}<0.05$.

Table 2. Tests of Between-Subject Effects for Outcome.

\begin{tabular}{|c|c|c|c|c|c|c|c|c|c|c|c|c|c|c|}
\hline \multirow[b]{2}{*}{ Cluster (Code) } & \multicolumn{7}{|c|}{ Therapist } & \multicolumn{7}{|c|}{ Patient } \\
\hline & df & $\begin{array}{c}\text { Poor } \\
\text { outcome } \\
\text { mean }\end{array}$ & $\begin{array}{c}\text { Good } \\
\text { outcome } \\
\text { mean }\end{array}$ & $\begin{array}{l}\text { Mean } \\
\text { square }\end{array}$ & $\mathbf{F}$ & Sig. & $\begin{array}{c}\text { Part. } \\
\eta^{2}\end{array}$ & df & $\begin{array}{c}\text { Poor } \\
\text { outcome } \\
\text { mean }\end{array}$ & $\begin{array}{c}\text { Good } \\
\text { outcome } \\
\text { mean }\end{array}$ & $\begin{array}{l}\text { Mean } \\
\text { square }\end{array}$ & $\mathbf{F}$ & Sig. & $\begin{array}{c}\text { Part. } \\
\eta^{2}\end{array}$ \\
\hline 1. Emancipate-Separate & 1 & 0.01 & 0.08 & 1.75 & 7.64 & $0.01 *$ & 0.00 & 1 & 0.12 & 0.04 & 0.66 & 2.99 & 0.16 & 0.00 \\
\hline 2. Affirm-Disclose & 1 & 0.28 & 0.88 & 290.93 & 163.79 & $0.00 *$ & 0.01 & 1 & 0.43 & 0.75 & 171.16 & 80.29 & $0.00 *$ & 0.01 \\
\hline 3. Active love-Reactive love & 1 & 0.02 & 0.05 & 0.99 & 6.10 & $0.04 * *$ & 0.01 & 1 & 0.00 & 0.04 & 2.16 & 20.29 & $0.00 *$ & 0.02 \\
\hline 4. Protect-Trust & 1 & 0.44 & 0.58 & 71.28 & 42.64 & $0.00 *$ & 0.02 & 1 & 0.10 & 0.75 & 701.90 & 543.54 & $0.00 *$ & 0.03 \\
\hline 5. Control-Submit & 1 & 0.17 & 0.35 & 2.73 & 2.68 & 0.40 & 0.01 & 1 & 0.04 & 0.00 & 3.08 & 4.18 & 0.12 & 0.00 \\
\hline 6. Blame-Sulk & 1 & 0.00 & 0.00 & 0.00 & 0.11 & 1.00 & 0.00 & 1 & 0.04 & 0.00 & 7.65 & 150.29 & $0.00^{*}$ & 0.01 \\
\hline 7. Attack-Recoil & 1 & - & - & 0.00 & - & - & - & 1 & 0.01 & 0.00 & 7.65 & 150.29 & $0.00 *$ & 0.01 \\
\hline 8. Ignore-Wall-off & 1 & 0.00 & 0.01 & 0.02 & 2.58 & 0.40 & 0.00 & 1 & 0.14 & 0.00 & 0.02 & 0.68 & 0.41 & 0.00 \\
\hline 9. Mixed interdependence & 1 & 0.00 & 0.00 & 0.00 & 0.00 & 1.00 & 0.00 & 1 & 0.00 & 0.13 & 29.04 & 91.93 & $0.00 *$ & 0.01 \\
\hline 10. Mixed focus & 1 & 0.00 & 0.00 & 149.46 & 0.19 & 1.00 & 0.00 & 1 & - & - & - & - & - & - \\
\hline
\end{tabular}

*, significant at $\mathrm{p}<0.01 ; *$, significant at $\mathrm{p}<0.05$. 
looking at Table 1, the second and third column of each section (i.e., the therapists' and the patients') show mean scores for the Other and Self focus, respectively. When looking at Table 2, the second and third column of each section (i.e., the therapists' and the patients') show mean scores for poor and good outcome, respectively.

Regarding the therapists, multivariate tests revealed the presence of significant differences in cluster scores based on focus $[F(9,13,163)=1,195.72, p<0.001, V=0.02$, partial $\left.\eta^{2}=0.02\right]$, outcome $[F(9,13,163)=574.97, p<0.001$, $V=0.01$, partial $\left.\eta^{2}=0.01\right]$, as well as the combination of focus * outcome $[F(9,13,163)=670.86, p<0.001, V=0.01$, partial $\left.\eta^{2}=0.01\right]$.

Regarding the patients, multivariate tests revealed significant scores for focus $[F(9,16,438)=162.83, p<0.001$, $V=.73$, partial $\left.\eta^{2}=.73\right]$, outcome $[F(9,16,438)=221.52$, $p<0.001, V=0.09$, partial $\left.\eta^{2}=0.09\right]$, along with significant interaction effects of focus * outcome $[F(9$, $16,438)=156.10, p<0.001, V=0.71$, partial $\left.\eta^{2}=0.71\right]$

As shown in Table 1, therapists were engaged in both high (cluster 2.1, separate) and low (cluster 2.5, submit) autonomy-taking intransitive transactions. In other words, they separated themselves from and deferred to the other as well. Therapists also made use of intransitive disclosure (cluster 2.2). On the other hand, when focusing on the Other (i.e., the patient), therapists mainly exerted a medium level of control (see mixed interdependence code), while granting protection (cluster 1.4, protect). These results indicate that therapists were assuming a neutrally controlling yet encouraging and supportive stance towards their clients. Therapist scores regarding cluster 7 (i.e., attack and recoil) were only found for poor-outcome cases, therefore further comparisons were not possible. On their side, patients used Self autonomy-taking stances, both in an interdependent (cluster 2.1, separate) and noninterdependent (cluster 2.7, recoil) manner. Patients also adopted an affiliative stance towards the Self in that they showed trust and reliance (cluster 2.4, trust). When focusing on the Other (i.e., the therapist), patients adopted a controlling (cluster 1.5, control, as well as mixed interdependence code) attitude and interacted both in a normal adaptive (cluster 1.3, active love) and maladaptive (clusters 1.6, blame) way. In other words, patients interdependently separated themselves (cluster 2.1) from the therapists showing either trust (cluster 2.4) towards the process or an act of recoiling (cluster 2.7). They also tried to control the setting (cluster 1.5 and mixed interdependence code), sought to bond with the therapist (cluster 1.3) or, on the contrary, blamed him/her (cluster 1.6). Mixed focus transactions, that is, transactions that simultaneously focus on the Other and the Self, were only found in pooroutcome patients, therefore further comparisons were not possible and will not be shown in any of the Tables.

As shown in Table 2, therapists treating good-outcome cases used behavioral clusters located in the first half of the SASB model (i.e., cluster 1, emancipate/separate; cluster 2, affirm/disclose; cluster 3, active/reactive love; cluster 4 , protect/trust) to a greater extent if compared to therapists treating poor-outcome cases. In other words, therapists in the good-outcome group tended to promote differentiation by granting neutral autonomy (cluster 1, emancipate/separate) and moderate affirmation (cluster 2, affirm/disclose), as well as adopting a loving (cluster 3, active/reactive love) and nurturing (cluster 4, protect/trust) attitude. Similarly, good-outcome patients adopted stances such as affirm/disclose (cluster 2), active/reactive love (cluster 3), and protect/trust (cluster 4). That is to say they tended to show affection (cluster 3) and trust and reliance (cluster 4) towards the therapist, while seeking affirmation and autonomy (cluster 2 and mixed interdependence code). On their end, poor-outcome patients were more prone to adopt hostile interpersonal patterns by belittling the other or feeling belittled (cluster 6 , blame/sulk), as well as withdrawing (cluster 7 ,

Table 3. Tests of Between-Subject Effects for Focus * Outcome.

Therapist

\begin{tabular}{lccccccccccc}
\hline Cluster (Code) & df & Mean square & $\mathbf{F}$ & Sig. & Part. $\boldsymbol{\eta}^{2}$ & df & Mean square & F & Sig. & Part. $\boldsymbol{\eta}^{\mathbf{2}}$ \\
\hline 1. Emancipate-Separate & 1 & 1.84 & 8.06 & $0.04^{* *}$ & 0.00 & 1 & 1.45 & 6.58 & $0.03^{* *}$ & 0.00 \\
\hline 2. Affirm-Disclose & 1 & 301.23 & 169.59 & $0.00^{*}$ & 0.02 & 1 & 369.19 & 173.19 & $0.00^{*}$ & 0.01 \\
\hline 3. Active love-Reactive love & 1 & 0.92 & 5.67 & 0.08 & 0.01 & 1 & 1.27 & 11.97 & $0.00^{*}$ & 0.04 \\
\hline 4. Protect-Trust & 1 & 106.61 & 63.77 & $0.00^{*}$ & 0.01 & 1 & 598.35 & 463.36 & $0.00^{*}$ & 0.00 \\
\hline 5. Control-Submit & 1 & 7.26 & 7.12 & 0.06 & 0.01 & 1 & 1.12 & 1.51 & 0.44 & 0.00 \\
\hline 6. Blame-Sulk & 1 & 0.00 & 0.11 & 1.00 & 0.00 & 1 & 3.97 & 77.96 & $0.00^{*}$ & 0.01 \\
\hline 7. Attack-Recoil & 1 & 0.00 & - & - & - & 1 & 3.97 & 77.96 & $0.00^{*}$ & 0.01 \\
\hline 8. Ignore-Wall-off & 1 & 0.14 & 3.24 & 0.21 & 0.00 & 1 & 0.03 & 1.17 & 0.44 & 0.00 \\
\hline 9. Mixed interdependence & 1 & 0.00 & 0.00 & 1.00 & 0.00 & 1 & 29.04 & 91.93 & $0.00^{*}$ & 0.01 \\
\hline 10. Mixed focus & 1 & 149.46 & 0.19 & 1.00 & 0.00 & 1 & - & - & - & - \\
\hline
\end{tabular}

${ }^{*}$, significant at $\mathrm{p}<0.01 ;{ }^{* *}$, significant at $\mathrm{p}<0.05$. A multiplicity correction was performed to control the false discovery rate using the Holm-Bonferroni method. 
attack/recoil) from the setting and counter-reacting to it (cluster 7, attack).

When independent variable interactions were considered (see Table 3), therapists treating good-outcome cases were shown to differentiate themselves (cluster 2.1, separate), used disclosure (cluster 2.2, disclose), and adopted a nurturing (cluster 1.4, protect) stance towards their clients. Similarly, good-outcome patients showed both affiliative and autonomy-seeking behaviors; specifically, they adopted transitive loving (cluster 1.3, active love) and transitive protecting (cluster 1.4, protect) interaction styles, while seeking moderate affirmation (cluster 1.2, affirm) towards the therapist and wanting to exert a transitive control (mixed interdependence code). In contrast, poor-outcome patients adopted autonomy-taking attitudes directed towards the Self and, therefore, tried to separate and assert themselves (clusters 2.1, separate), not to mention withdraw from the therapy (cluster 2.7, recoil), while using disapproving interactions towards the therapist (cluster 1.6, blame).

\section{Discussion}

When implementing and writing this study, we purposely decided to maintain a highly specific focus of investigation so as to avoid misinterpreting or worse compromising our findings regarding relational processes in therapy. For example, interpersonal transactions within the patient-therapist dyad - whether friendly or hostileshould be distinguished from friendliness and hostility that patients (or therapists) express regarding other people or general life circumstances (Anderson et al., 2012). Even though it is not the focus of the present study, we are well aware that, for some personality organizations (e.g., the anxious-obsessive or depressive-masochistic ones, that, on closer inspection, echo the psychopathological spectrum characterizing our sample), being able to freely express negative feelings and hostility, even when they are directed towards the therapy or the therapist, might be a chance for the patient's personal growth (Margola, 2020; McWilliams, 2011).

In the current study, while it is true that the distinction between good- and poor-outcome treatments is obvious and, at times, even predictable, especially when data are interpreted in light of the focus * outcome interaction (see Table 3), it is important to notice that such distinction is mostly based on the patients' behaviors as if the therapists were not part of the picture and the final outcome was dependent only on the patients themselves. This idea may seem speculative, but we believe that even a lack of findings deserves attention. In this view, the complementarity between the patients' and therapists' respective positions that we previously defined as predictable did not seem a true interpersonal complementarity. However, this warrants further investigation. The underlying question is: Do patients in general (see Table 1) and poor-outcome pa- tients in particular (see Table 2) engage in self-withdrawing as well as belittling and blaming (i.e., hostile) behavioral patterns as a result of an intrinsic resistance to change (Beutler et al., 2001) or, rather, are these behaviors elicited by the absence of a (complementary) intervention on the therapists' side (see Tables 2 and 3)? Is the fact that therapists are not in the picture caused by the patients' often discouraging behavior (see Table 1) (von der Lippe et al., 2008), or is it rather due to the therapists' own subtle self-submission (see again, Table 1) and/or their failed attempt to gain control (see Tables 1 and 2) over the setting (Tanzilli et al., 2017)?

Similarly, while emancipation and separation are not hostile per se, they indicate that the client is pulling away interpersonally from the therapist or, else, they might as well signal a psychological growth and increased selfconfidence and agency on the patients' side, especially in the long term (Wong \& Pos, 2012). This last presupposition might be reinforced by the fact that, in the current study, good-outcome patients do not only show transitive loving and protective behaviors (see Table 3 ), but also tangible signs of affirmation (see Tables 2 and 3 ) and control (see again, Tables 2 and 3 ).

We wonder what forms complementarity might assume. In other words, we wonder whether it has its autonomy (i.e., it only depends on one of the two interlocutors - the patient in our case), or whether it is the outcome of a relational process in which the therapist can either show neutral or friendly behaviors (see Table 2) or adopt a subjective position (i.e., self-oriented) by separating and disclosing himself/herself (see Tables 1 and 3) and protecting the patient (see Table 3; see also, Table 1) (Lingiardi et al., 2018). Although generalized, our preliminary finding indicating that not all the therapists' transactions were directed towards the Other ( $23 \%$ of them, i.e., about $1 / 4$, are intransitive and thus focused on the Self) seems to go in this direction. This is especially true in the case of the poor-outcome group, somehow suggesting a negative complementarity, that is an overthrowing of what we should expect from a therapist (i.e., transitively focusing on the Other). However, our data do not allow us to understand what direction this negative reversed complementarity takes (see Tables 2 and 3). Such a behavior might be connected to the fact that therapists tended to separate themselves from and defer to the other at the same time (see Table 1). The same is true for poor-outcome patients, for whom the direction taken by transitive behaviors is expressed by belittling and withdrawing; once again, however, it is difficult to understand whether this is due to: i) something intrinsic to the patient; ii) an action undertaken by the therapist that failed in influencing the patient; iii) the bidirectional and truly complementary nature of the patient-therapist system (Critchfield et al., 2007; Orlinsky et al., 2004). Although plausible, this latter hypothesis cannot be unquestionably confirmed by the current study. 
From a different point of view, interpretation is generally used with caution and parsimony, especially in the first phases of therapy and especially if it concerns transference (Anderson et al., 2012). In this sense, interpretations might take the form of a reconstruction or reframing of the patient's thoughts (McWilliams, 2011) and seem to work best when preceded by supportive interventions, focused reflective listening, and the therapist's self-disclosure (Gabbard et al., 1994). The current study does not include any coded measures of interpretation and its (well known and extensively investigated) potentials, however, this construct is indirectly analyzed through self-disclosure (see cluster 2.2, disclose). When used clinically and with a therapeutic aim, self-disclosure is always directed at the patient, that is, it is made having the patient in mind (e.g., "I am feeling overwhelmed, much like the child in your dream"). While this type of clinical intervention, especially when used to interpret the transference, has not yet accumulated a critical mass of well-designed studies, it has shown encouraging results in terms of positive effects on the overall treatment outcome (e.g., Anderson et al., 2012).

Our results show that therapists initiated this specific action towards their patients (see Tables 1 and 2, and particularly, Table 3). Thus, it would be important to understand whether the use of self-disclosure signals a congruent underlying interpersonal complementarity (i.e., it implies the therapist being receptive), or if it is rather a form of self-defense, that is, the tangible sign of the therapist's weakening him/herself (von der Lippe et al., 2008) in the face of the dyad's asymmetry. As if-when in difficulty - therapists disengage themselves and focus inward, in a self-soothing attempt (Accordini et al., 2017; Ackerman \& Hilsenroth, 2001; Tanzilli et al., 2017). What we know for certain is that self-disclosure is used rather frequently by the therapists in our sample, especially when treating good-outcome cases (see Tables 2 and 3). While such an outcome confirms the bidirectionality (complementary) of the patient-therapist interaction, it fails in predicting who initiates or drives such an interaction, that is, the patient or the therapist (Margola et al., 2018).

Let's now focus on the clinician's experience. All the therapists participating in this study had extensive clinical experience (17 years on average). Not only we can say that, in general, experienced therapists are subject to failure but also that such failure seems to be connected to a lack of incisiveness on their side (see Tables 2 and 3). In other words, poor-outcome cases seem to be characterized by therapists acting ambiguously and leading to haphazard and noncomplementary transactions. By noncomplementary transactions, we refer here to the therapist's failure in directing and actively leading the therapeutic process (Caspar et al., 2005; Margola et al., 2018). In this perspective, our study confirms several empirical investigations (Henry, 1996; Henry et al., 1986, 1990; Henry
\& Strupp, 1994; Hilliard, Henry, \& Strupp, 2000; von der Lippe et al., 2008) that analyzed hostility within the therapeutic relationship among well-trained therapists. When reflecting on what therapists are typically expected to do (i.e., focusing on the Other transitively), our subjects proved capable of showing protection (see Tables 1 and 3 ), while also adopting a controlling stance; however, such control sometimes resulted in disaffiliative unfriendly behaviors (see Table 1), as well as in a tendency to focus on the Self in the nonresponders group (see preliminary chi-squared testing). In conclusion, this research shows that even well-trained therapists are somehow vulnerable to engaging in disaffialitive and hostile dynamics (Accordini et al., 2017; Ackerman \& Hilsenroth, 2001; Henry et al., 1990; Tanzilli et al., 2017), and, likely, this should be appraised as the sign of a progressively "therapists' discouragement" (von der Lippe et al., 2008, p. 430). Thus, the lack of caution that even well-trained therapists seem to show especially when dealing with challenging patients displaying dysfunctional behavioral patterns (Margola, 2020; Norcross \& Wampold, 2011) contradicts the idea according to which therapists should adopt a countertransferencially-disciplined attitude (Gabbard et al., 1994; Høglend \& Gabbard, 2012), that is, should avoid countertransferential acting out while maintaining a more balanced and poised attitude.

Based on this general overview of the research results, we will now focus on therapy outcomes more in detail. Poor-outcome patients showed signs of blame and hostile aggression (see Tables 1, 2, and 3), tending towards control over the therapist (see Table 1) or, on the contrary, self-withdrawal (see Tables 1, 2, and 3) (Fava \& Vigorelli, 2006; von der Lippe et al., 2008), thus confirming that patients in low-change treatments show higher levels of disaffiliative and counteracting behaviors (Henry et al., 1990). Research shows that such relational patterns are particularly resistant to change because patients are used to being treated this way by a caregiver (Benjamin, 2002; Beutler et al., 2001; von der Lippe et al., 2008). If this adversarial relational pattern were to change, it would imply losing the caregiver, and - in a way - it is better to have an aggressive or neglectful parent than no parent (Amadei, 2001). The contrary happened for complex communications (i.e., mixed interdependence code): Patients tended to use mixed autonomy styles in the good-outcome group as well as across the two groups transversally, that is to say this type of behaviors were not strictly and predictively discriminative (Critchfield et al., 2007). In particular, patients took control over the setting (including the therapist) irrespectively of the treatment outcome (see Tables 1 and 3, by way of cluster 5 and mixed interdependence code). This finding partially contrasts with Benjamin's hypothesis $(2002 ; 2003)$ where patients' attempt to control the setting and overrule the therapist generally leads to unfavorable outcomes, thus making her argument regarding complementarity partly less unilateral 
(see also, Caspar et al., 2005; Critchfield et al., 2007).

On their end, good-outcome patients showed tangible signs of friendly affiliative transactions (see Tables 2 and 3 ) and minimal signs (vs. no sign) of transitive blaming (see Table 2) as well as transitive affirming (see Table 3). Moreover, they were exhibiting higher intransitive separateness scores (see Tables 2 and 3) compared to the patients in the treatment failure group (Hilliard et al., 2000). In terms of separateness, our data evoke the presence of a complementary schema between the patients' and therapist's behaviors (see Tables 2 and 3), although the correlational nature of the analyses makes this type of interpretation somewhat tentative. We wonder whether these transactions were the result of one of the two members' behaviors per se or the consequence of therapy processes and underlying interrelations among the observational measures used in this study. The same difficulty occurs in interpreting the therapeutic relationship as being curative when emancipation, autonomy, warm encouragement, and safety (see Tables 2 and 3 ) are granted, that is to say when considering commonly unspecific interventions (Critchfield et al., 2007), well beyond any type of theoretically- and empirically-informed clinical techniques (Beutler, 2000; Henry \& Strupp, 1994; Norcross \& Wampold, 2011). However, our results do suggest the role of affiliative processes in characterizing and, to some extent, fostering positive treatment outcomes (Benjamin, 2002; Hill \& Knox, 2009; Hilliard et al., 2000).

What is the underlying risk? On one hand, therapists - even experienced therapists - might end up using unfriendly controlling stances as well as self-submitting behaviors towards their patients, especially those nonresponding to treatment (see Table 2). On the other hand, patients' controlling behaviors - despite being present also in the good-outcome patient group (see Tables 2 and 3) - may turn to overt hostility towards the therapists (see Table 1). As clinicians as well as clinical researchers, we are prone to think that managing and controlling the clinical context and its rules is key (Norcross \& Wampold, 2011). However, controlling the relationship rather than the therapeutic context evokes the risk of confounding these two entities (Ackerman \& Hilsenroth, 2001; Margola et al., 2018; Norcross \& Wampold, 2011; von der Lippe et al., 2008).

\section{Limitations and conclusions}

Beyond the correlational nature of the study, the impossibility of determining the antecedents and consequents influencing the patient-therapist complementarity, and of establishing cause-effect relations already mentioned above, another limitation must be highlightedi.e., the exclusive research focus on a one-year timeframe without taking into account the four individual temporal segments (quarters). Future research should investigate the differences in patient-therapist interactions comparing early and later therapy sessions, as well as considering the potential influence of additional dependent or independent intervening variables (e.g., the transdiagnostic personality styles on the patients' side; Margola, 2020; Pincus et al., 1999).

Another limitation affecting the current research is connected to the specificity of the clinical population taking part in the study: Having exclusively involved patients with a diagnosed mood or anxiety disorder may limit the generalizability of our findings to nonclinical samples or patients suffering from other disorders.

Overall, the focus of the present study is undoubtedly interpersonal (given the coding system adopted), but it is not strictly intersubjective (as paired sequential analyses were not undertaken). These limitations will be partially resolved in a secondary analysis of the same research data (i.e., a number near to 30,000 thought units when patient and therapist transactions are summed), yet using a different methodology (i.e., sequence chains aimed at determining the nature and features of the patient-therapist proximal behaviors, identifying who and what follows who and what; see Benjamin, 1979).

That said, the SASB model remains - even after almost half a century - one of the most reliable instruments to study and assess the treatment processes and patienttherapist interpersonal relationships. Its reliability allows one to draw both theoretical conclusions (across various clinical orientations), as well as practical implications (specifically regarding our full understanding of therapeutic complementarity, beyond its stereotypical conception - that circumscribes it to the mere act of responding to a patient's action with a similarly affectively connoted behavior - as well as our understanding of treatment failures) (see Benjamin et al., 2006; Caspar et al., 2005; Fava $\&$ Vigorelli, 2006). This further denotes the predictive role of observational measures such as the ones encompassing the SASB model, so that positive and negative predictors could be carefully detected in advance (Beutler, 2000; Frommer \& Rennie, 2001; Margola et al., 2018; Wong \& Pos, 2012).

\section{References}

Accordini, M., Browning, S., Gennari, M., McCarthy, K., \& Margola, D. (2017). Till the ocean do us part: Italian and American therapists' representations of stepfamilies in treatment. Research in Psychotherapy: Psychopathology, Process and Outcome, 20, 187-200. doi: 10.4081/ripppo.2017.271

Ackerman, S. J., \& Hilsenroth, M. J. (2001). A review of therapist characteristics and techniques negatively impacting the therapeutic alliance. Psychotherapy, 38, 171-185. doi: 10.1037/0033-3204.38.2.171

Ahmed, M., Westra, H. A., \& Constantino, M. J. (2012). Early therapy interpersonal process differentiating clients high and low in outcome expectations. Psychotherapy Research, 22, 731-745. doi: 10.1080/10503307.2012.724538

Aliprandi, M., Capelli, L., \& Marchesi, L. (2009). Analisi Strut- 
turale del Comportamento Sociale (SASB) [Structural Analysis of Social Behavior (SASB)]. In M. Vigorelli (Ed.), Laboratorio didattico per la ricerca in psicoterapia $[$ The psychotherapy research lab] (pp. 14-22). Milan, Italy: Cortina.

Allport, G. W. (1937). Personality: A psychological interpretation. New York, NY: Holt.

Amadei, G. (2001). Il paradigma celato. Il modello interpersonale nella psicologia dinamica [The hidden paradigm: Interpersonal models in dynamic psychology]. Milan, Italy: Unicopli.

American Psychiatric Association (2000). Diagnostic and statistical manual of mental disorders: Text revision (4th ed.). Washington, DC: American Psychiatric Association.

Anchin, J. C., \& Kiesler, D. J. (1982). Handbook of interpersonal psychotherapy. New York, NY: Pergamon.

Anderson, T., Knobloch-Fedders, L. M., Stiles, W. B., Ordoñez, T., \& Heckman, B. D. (2012). The power of subtle interpersonal hostility in psychodynamic psychotherapy: A speech acts analysis. Psychotherapy Research, 22, 348-362. doi: 10.1080/10503307.2012.658097

Benjamin, L. S. (1974). Structural Analysis of Social Behavior. Psychological Review, 81, 392-425. doi: 10.1037/h0037024

Benjamin, L. S. (1979). Use of Structural Analysis of Social Behavior (SASB) and Markov chains to study dyadic interactions. Journal of Abnormal Psychology, 88, 303-319. doi: 10.1037/0021-843X.88.3.303

Benjamin, L. S. (1984). Principles of prediction using Structural Analysis of Social Behavior. In R. A. Zucker, J. Aronoff, \& A. J. Rabin (Eds.), Personality and the prediction of behavior (pp. 121-173). New York, NY: Academic Press.

Benjamin, L. S. (1994). SASB: A bridge between personality theory and clinical psychology. Psychological Inquiry, 5, 273-316. doi: 10.1207/s15327965pli0504_1

Benjamin, L. S. (2002). Interpersonal diagnosis and treatment of personality disorders (2nd ed.). New York, NY: Guilford.

Benjamin, L. S. (2003). Interpersonal reconstructive therapy: Promoting change in nonresponders. New York, NY: Guilford.

Benjamin, L. S., Rothweiler, J. C., \& Critchfield, K. L. (2006). The use of Structural Analysis of Social Behavior (SASB) as an assessment tool. Annual Review of Clinical Psychology, 2, 83-109. doi: 10.1146/annurev.clinpsy.2.022305.095337

Beutler, L. E. (2000). David and Goliath: When empirical and clinical standards of practice meet. American Psychologist, 55, 997-1007. doi: 10.1037/0003-066X.55.9.997

Beutler, L. E., Rocco, F., Moleiro, C. M., \& Talebi, H. (2001). Resistance. Psychotherapy, 38, 431-436. doi: 10.1037/00333204.38.4.431

Beutler, L. E., Malik, M., Alimohamed, S., Harwood, T. M., Talebi, H., Noble, S., \& Wong, E. (2004). Therapist variables. In M. J. Lambert (Ed.), Bergin and Garfield's handbook of psychotherapy and behavior change (5th ed., pp. 227-306). New York, NY: Wiley.

Bion, W. R. (1963). Elements of psycho-analysis. New York, NY: Jason Aronson.

Blomberg, J., Lazar, A., \& Sandell, R. (2001). Long-term outcome of long-term psychoanalytically oriented therapies: First findings of the Stockholm outcome of psychotherapy and psychoanalysis study. Psychotherapy Research, 11, 361-382. doi: 10.1093/ptr/11.4.361

Capelli, L., Fava, E., Taglietti, S., Aliprandi, M., Arduini, L., Freni, S., Schadee, H., \& Vigorelli, M. (2005). Relazione in- terpersonale ed esiti terapeutici: applicazioni del metodo SASB [Interpersonal relationship and therapeutic outcome: Applications of the SASB method]. Ricerca in Psicoterapia, 8, 195-236.

Caspar, F., Grossmann, C., Unmüssig, C., \& Schramm, E. (2005). Complementary therapeutic relationship: Therapist behavior, interpersonal patterns, and therapeutic effects. Psychotherapy Research, 15, 91-102. doi: 10.1080/10503300512331327074

Coady, N. F. (1991). The association between client and therapist interpersonal processes and outcomes in psychodynamic psychotherapy. Research on Social Work Practice, 1, 122 138. doi: 10.1177/104973159100100202

Cohen, J. (1968). Weighted kappa: Nominal scale agreement with provision for scaled disagreement or partial credit. Psychological Bulletin, 70, 213-220. doi: 10.1037/h0026256

Constantino, M. J. (2000). Interpersonal process in psychotherapy through the lens of the Structural Analysis of Social Behavior. Applied and Preventive Psychology, 9, 153-172. doi: 10.1016/S0962-1849(05)80002-2

Critchfield, K. L., Henry, W. P., Castonguay, L. G., \& Borkovec, T. D. (2007). Interpersonal process and outcome in variants of cognitive-behavioral psychotherapy. Journal of Clinical Psychology, 63, 31-51. doi: 10.1002/jclp.20329

Derogatis, L. R. (1994). Symptom Checklist-90-R: Administration, scoring, and procedures manual (3rd ed.). Minneapolis, MN: National Computer Systems.

Fava, E., \& Vigorelli, M. (2006). La valutazione del processo terapeutico attraverso un modello circomplesso: la SASB di Lorna Benjamin [The evaluation of therapeutic processes through a circumplex model: The Lorna Benjamin's SASB model]. In N. Dazzi, V. Lingiardi, \& A. Colli (Eds.), La ricerca in psicoterapia. Modelli e strumenti [Psychotherapy research: Models and instruments] (pp. 691-711). Milan, Italy: Cortina.

Ferrari, A., Pinzi, C., Camarda, P., \& Roustayan, C. (2005). Valutazione a lungo termine dell'effectiveness della psicoterapia supportivo-espressiva in un contesto pubblico: esiti, follow-up, drop-out e predittori [Supportive-expressive psychotherapy long-term evaluation and effectiveness in an outpatients' clinic: Outcomes, follow-ups, dropouts, and predictors]. Giornale Italiano di Psicopatologia, 11, 32-37.

Fleiss, J. L., \& Cohen, J. (1973). The equivalence of weighted kappa and the intraclass correlation coefficient as measures of reliability. Educational and Psychological Measurement, 33, 613-619. doi: 10.1177/001316447303300309

Freud, S. (1920). Beyond the pleasure principle. S.E., Vol. 18 (pp. 1-64). London, UK: Hogarth Press, 1991. doi: 10.1037/11189-001

Frommer, J., \& Rennie, D. L. (2001). Qualitative psychotherapy research: Methods and methodology. Lengerich, Germany: Pabst Science.

Gabbard, G. O., Horwitz, L., Allen, J. G., Frieswyk, S., Newsom, G., Colson, D. B., et al. (1994). Transference interpretation in the psychotherapy of borderline patients: A high-risk, high-gain phenomenon. Harvard Review of Psychiatry, 2, 59-69.

Gelso, C. J. (2009). The real relationship in a postmodern world: Theoretical and empirical explorations. Psychotherapy Research, 19, 253-264. doi: 10.1080/10503300802389242

Henry, W. P. (1996). The Structural Analysis of Social Behavior as a common metric for programmatic psychotherapy research. Journal of Consulting and Clinical Psychology, 64, 1263-1275. doi: 10.1037/0022-006X.64.6.1263

Henry, W. P., \& Strupp, H. H. (1994). The therapeutic alliance 
as interpersonal process. In A. O. Horvath, \& L. S. Greenberg (Eds.), The working alliance: Theory, research, and practice (pp. 51-84). New York, NY: Wiley.

Henry, W. P., Schacht, T. E., \& Strupp, H. H. (1986). Structural Analysis of Social Behavior: Application to a study of interpersonal process in differential psychotherapeutic outcome. Journal of Consulting and Clinical Psychology, 54, 27-31. doi: 10.1037/0022-006X.54.1.27

Henry, W. P., Schacht, T. E., \& Strupp, H. H. (1990). Patient and therapist introject, interpersonal process, and differential psychotherapy outcome. Journal of Consulting and Clinical Psychology, 58, 768-774. doi: 10.1037/0022-006X.58.6.768

Henry, W. P., Schacht, T. E., Strupp, H. H., Butler, S. F., \& Binder, J. L. (1993). Effects of training in time-limited dynamic psychotherapy: Mediators of therapists' responses to training. Journal of Consulting and Clinical Psychology, 61, 441-447. doi: 10.1037/0022-006X.61.3.441

Hill, C. E., \& Knox, S. (2009). Processing the therapeutic relationship. Psychotherapy Research, 19, 13-29. doi: 10.1080/10503300802621206

Hilliard, R. B., Henry, W. P., \& Strupp, H. H. (2000). An interpersonal model of psychotherapy: Linking patient and therapist developmental history, therapeutic process, and types of outcome. Journal of Consulting and Clinical Psychology, 68, 125-133. doi: 10.1037/0022-006X.68.1.125

Hilsenroth, M. J., \& Segal, D. L. (Eds.) (2004). Comprehensive handbook of psychological assessment. Vol. 2. Personality assessment. New York, NY: Wiley.

Høglend, P., \& Gabbard, G. O. (2012). When is transference work useful in psychodynamic psychotherapy? A review of empirical research. In R. A. Levy, J. S. Ablon, \& H. Kächele (Eds.), Psychodynamic psychotherapy research: Evidencebased practice and practice-based evidence (pp. 449-470). Totowa, NJ: Springer. doi: 10.1007/978-1-60761-792-1_26

Horney, K. (1936). The problem of the negative therapeutic reaction. Psychoanalytic Quarterly, 5, 29-44. doi: 10.1002/j.2167-4086.2007.tb00244.x

Horvath, A. O., Del Re, A. C., Flückiger, C., \& Symonds, D. (2011). Alliance in individual psychotherapy. Psychotherapy, 48, 9-16. doi: 10.1037/a0022186

Howard, K. I., Kopta, S. M., Krause, M. S., \& Orlinsky, D. E. (1986). The dose-effect relationship in psychotherapy. American Psychologist, 41, 159-164. doi: 10.1037/0003066X.41.2.159

Jacobson, N. S. (1988). Defining clinically significant change: An introduction. Behavioral Assessment, 10, 131-132.

Jacobson, N. S., Follette, W. C., \& Revenstorf, D. (1984). Toward a standard definition of clinically significant change. Behavior Therapy, 17, 308-311. doi: 10.1016/s00057894(86)80061-2

Keijsers, G. P., Schaap, C. P., \& Hoogduin, C. A. (2000). The impact of interpersonal patient and therapist behavior on outcome in cognitive-behavior therapy: A review of empirical studies. Behavior Modification, 24, 264-297. doi: 10.1177/0145445500242006

Lambert, M. J., \& Barley, D. E. (2001). Research summary on the therapeutic relationship and psychotherapy outcome. Psychotherapy, 38, 357-361. doi: 10.1037/0033-3204.38.4.357

Lambert, M. J., \& Ogles, B. M. (2004). The efficacy and effectiveness of psychotherapy. In M. J. Lambert (Ed.), Bergin and Garfield's handbook of psychotherapy and behavior change (5th ed., pp. 139-193). New York, NY: Wiley.

Lepper, G., \& Riding, N. (2006). Researching the psychotherapy process: A practical guide to transcript-based methods. London, UK: Palgrave Macmillan.

Lingiardi, V., \& Muzi, L. (2018). Il Manuale Diagnostico Psicodinamico (PDM-2): un'occasione di dialogo interdisciplinare [The Psychodynamic Diagnostic Manual (PDM-2): An opportunity to enhance an interdisciplinary dialogue]. Giornale Italiano di Psicologia, 45, 781-804. doi: 10.1421/92989

Lingiardi, V., Muzi, L., Tanzilli, A., \& Carone, N. (2018). Do therapists' subjective variables impact on psychodynamic psychotherapy outcomes? A systematic literature review. Clinical Psychology and Psychotherapy, 25, 85-101. doi: 10.1002/cpp.2131

Lord, F. M., \& Novick, M. R. (1968). Statistical theories of mental test scores. Reading, MA: Addison-Wesley.

Luborsky, L., \& Crits-Christoph, P. (1990). Understanding transference. The CCRT method. New York, NY: Basic Books.

Luca M., Ruta S., Signorelli M., Petralia A., \& Aguglia E. (2015). Variabili psicologiche e consumo di alcol in un campione di studenti di medicina: differenze di genere [Psychological variables and alcohol consumption in a sample of students of medicine: Gender differences]. Rivista di Psichiatria, 50, 38-42. doi: 10.1708/1794.19536

Lutz, W., Lambert, M. J., Harmon, S. C., Tschitsaz, A., Schürch, E., \& Stulz, N. (2006). The probability of treatment success, failure, and duration: What can be learned from empirical data to support decision making in clinical practice? Clinical Psychology and Psychotherapy, 13, 223-232. doi: 10.1002/cpp.496

Mahrer, A. R. (1999). Embarrassing problems for the field of psychotherapy. Journal of Clinical Psychology, 55, 11471156. doi: 10.1002/(sici)1097-4679(199909)

Margola, D. (2020). I disturbi di personalità. Per una sintesi clinicamente fondata: il Basic and Continuum-focused Diagnostic Model (BCDM) [Personality disorders. Towards a clinically informative synthesis: The Basic and Continuumfocused Diagnostic Model (BCDM)]. In D. Margola, Introduzione alla psicopatologia. Dalla nosografia individuale al legame di coppia [Introduction to psychopathology: From individual nosography to the couple relationship] (pp. 1722). Milan, Italy: EDUCatt.

Margola, D., Donato, S., Accordini, M., Emery, R. E., \& Snyder, D. K. (2018). Dyadic coping in couple therapy process: An exploratory study. Family Process, 57, 324-341. doi: 10.1111/famp. 12304

McWilliams, N. (2011). Psychoanalytical diagnosis. Understanding personality structure in the clinical process. New York, NY: Guilford.

Norcross, J. C., \& Wampold, B. E. (2011). Evidence-based therapy relationships: Research conclusions and clinical practices. In J. C. Norcross (Ed.), Psychotherapy relationships that work: Evidence-based responsiveness (2nd ed., pp. 423-430). New York, NY: Oxford University Press.

Orlinsky, D. E., Rønnestad, M. H., \& Willutzki, U. (2004). Fifty years of psychotherapy process-outcome research: Continuity and change. In M. J. Lambert (Ed.), Bergin and Garfield's handbook of psychotherapy and behavior change (5th ed., pp. 307-389). New York, NY: Wiley.

Pincus, A. L., Dickinson, K. A., Schut, A. J., Castonguay, L. G., \& Bedics, J. (1999). Integrating interpersonal assessment and adult attachment using SASB. European Journal of Psychological Assessment, 15, 206-220. doi: 10.1027/10155759.15.3.206

Riviere, J. (1936). A contribution to the analysis of the negative 
therapeutic reaction. The International Journal of Psychoanalysis, 17, 304-320.

Samstag, L. W. (1998). Difficult dyads and unsuccessful treatments: A comparison of dropout, poor, and good outcome groups in brief psychotherapy. ProQuest Dissertations \& Theses.

Samstag, L. W., Muran, J. C., Wachtel, P. L., Slade, A., Safran, J. D., \& Winston, A. (2008). Evaluating negative process: A comparison of working alliance, interpersonal behavior, and narrative coherency among three psychotherapy outcome conditions. American Journal of Psychotherapy, 62, 165194. doi: 10.1176/appi.psychotherapy.2008.62.2.165

Schmitz, N., Hartkamp, N., Brinschwitz, C., Michalek, S., \& Tress, W. (2000). Comparison of the standard and the computerized versions of the Symptom Checklist (SCL-90-R): A randomized trial. Acta Psychiatrica Scandinavica, 102, 147-152. doi: 10.1034/j.1600-0447.2000.102002147.x

Schurle Bruce, A., \& Arnett, P. A. (2008). Longitudinal study of the Symptom Checklist 90-Revised in multiple sclerosis patients. The Clinical Neuropsychologist, 22, 46-59. doi: $10.1080 / 13854040601064518$

Stein, D. M., \& Lambert, M. J. (1984). On the relationship between therapist experience and psychotherapy outcome. Clinical Psychology Review, 4, 1-16.
Tanzilli, A., Muzi, L., Ronningstam, E., \& Lingiardi, V. (2017). Countertransference when working with narcissistic personality disorder: An empirical investigation. Psychotherapy, 54, 184-194. doi: 10.1037/pst0000111

Tasca, G. A., Foot, M., Leite, C., Maxwell, H., Balfour, L., \& Bissada, H. (2011). Interpersonal processes in psychodynamic-interpersonal and cognitive behavioral group therapy: A systematic case study of two groups. Psychotherapy, 48, 260-273. doi: 10.1037/a0023928

Thompson, K., Schwartzman, D., D’Iuso, D., Dobson, K. S., \& Drapeau, M. (2018). Client and therapist interpersonal behaviour in cognitive therapy for depression. Canadian Journal of Counselling and Psychotherapy, 52, 229-249.

von der Lippe, A. L., Monsen, J. T., Rønnestad, M. H., \& Eilertsen, D. E. (2008). Treatment failure in psychotherapy: The pull of hostility. Psychotherapy Research, 18, 420-432. doi: 10.1080/10503300701810793

Waddington, L. (2002). The therapy relationship in cognitive therapy: A review. Behavioural and Cognitive Psychotherapy, 30, 179-191. doi: 10.1017/S1352465802002059

Wong, K., \& Pos, A. E. (2012). Interpersonal processes affecting early alliance formation in experiential therapy for depression. Psychotherapy Research, 1, 1-11. doi: 10.1080/ 10503307.2012.708794 